\title{
Salt intake in children and its consequences on blood pressure
}

\author{
Sebastiano A. G. Lava • Mario G. Bianchetti • \\ Giacomo D. Simonetti
}

Received: 29 March 2014 / Revised: 23 July 2014 / Accepted: 24 July 2014 /Published online: 17 August 2014

(C) IPNA 2014

\begin{abstract}
Sodium is the most abundant extracellular cation and therefore pivotal in determining fluid balance. At the beginning of life, a positive sodium balance is needed to grow. Newborns and preterm infants tend to lose sodium via their kidneys and therefore need adequate sodium intake. Among older children and adults, however, excessive salt intake leads to volume expansion and arterial hypertension. Children who are overweight, born preterm, or small for gestational age and African American children are at increased risk of developing high blood pressure due to a high salt intake because they are more likely to be salt sensitive. In the developed world, salt intake is generally above the recommended intake also among children. Although a positive sodium balance is needed for growth during the first year of life, in older children, a sodiumpoor diet seems to have the same cardiovascular protective effects as among adults. This is relevant, since: (1) a blood pressure tracking phenomenon was recognized; (2) the development of taste preferences is important during childhood; and (3) salt intake is often associated with the consumption of sugar-sweetened beverages (predisposing children to weight gain).
\end{abstract}

S. A. G. Lava $\cdot$ G. D. Simonetti

Division of Pediatric Nephrology, University Children's Hospital

Bern, Bern, Switzerland

S. A. G. Lava • G. D. Simonetti

University of Bern, Bern, Switzerland

S. A. G. Lava • M. G. Bianchetti · G. D. Simonetti

Pediatric Department of Southern Switzerland, Bellinzona,

Switzerland

G. D. Simonetti $(\square)$

Pediatric Nephrology Unit, University Children's Hospital, Inselspital, 3010 Bern, Switzerland

e-mail: giacomo.simonetti@insel.ch
Keywords Salt · Sodium $\cdot$ Blood pressure $\cdot$ Hypertension · Tracking $\cdot$ Salt sensitivity

\section{Introduction}

The words salus (Latin for health) and salubris (healthy) underscore the role of salt in ancient Rome, where salt was regarded as a symbol of health and prosperity, likely because of its role in food preservation [1]. In the eyes of Homer, salt represented a divine substance [2], whereas it was a cornerstone of daily life in the Jewish-Christian tradition (Esdra 6,9; Esdra 7,22; Gb 6,6; Lv 2, 13; 2Re 2,21; Mt 5,13). Historically, salt was a precursor of coins (e.g., salt tax, 1Mac 10,29), and it led to the discovery of shipways and adventurous trips. In ancient Rome, soldiers were paid a specific quantity of salt (salarium) rather than gold or coins. Thus, salt was an important currency. The relevance of salt is also reflected in the name of numerous cities including Salzburg (Austria), Langensalza (Germany), Sandwich (England), and Saltcoats (Scotland). At the beginning of the late modern period, the salt tax was important; in fact, salt tax officers were decapitated during the French Revolution [3]. In several cultures around the world, salt (a white substance) is a symbol of the imperishable; it was an emblem of immortality and loyalty, which is reflected by the sharing of bread and salt with a guest, a tradition that remains alive in Slavic countries [3]. Salt is the spice par excellence because it provides taste and flavor to food. Finally, consider the Latin expression cum grano salis (literally, with a grain of salt), which means with common sense. An abundance of literature has appeared about the role of salt on blood pressure, throughout this review we consider and highlight some key papers focusing on this problem in childhood. 
Physiological aspects

Sodium, the most abundant extracellular cation, is pivotal in determining fluid balance [4]. The total sodium content of the adult human body is $\sim 80 \mathrm{mmol} / \mathrm{kg}$ of fat-free body weight [5]; this proportion is higher in newborns, infants, and children $[6,7]$. Fluid and sodium balances play a central role in regulating blood pressure and, potentially, in the development of arterial hypertension. Several factors modulate salt handling, such as - among others - activation of the sympathetic nervous system, hyperinsulinemia, hypercalcemia, acid-base balance [8], hyperaldosteronism [8, 9], leptin [10], genetic background, and maybe also circulating cardioglycosides [11]. Most of these systems ultimately work through the kidney, with the renin-aldosterone-angiotensin system playing a pivotal role in fluid and sodium homeostasis. This importance is suggested by several monogenetic hypertensive diseases [12]. Furthermore, it was demonstrated via transplantation experiments in both rats and humans that essential hypertension resolved after bilateral nephrectomy and kidney transplantation [13].

Newer data suggest that an extrarenal system may play a role in sodium handling. Elegant experiments by Titze and coworkers propose that sodium can be stored on negatively charged glycosaminoglycans in the skin interstitium, where it becomes osmotically inactive [14]. Thus, the skin interstitium might act as a negatively charged capacitor and fluid-buffering system able to store sodium without commensurate water retention. In this way, it could blunt accumulation of excess body fluid (and the resultant high blood pressure) following high salt intake [14]. Actually, sensing the accumulation of sodium cations, macrophages might be recruited and subsequently release vascular endothelial growth factor C (VEGFC), which stimulates hyperplasia of the cutaneous lymph capillary network, inducing local clearance of skin electrolytes (Fig. 1) [14, 15]. These mechanisms might be impaired or overwhelmed in salt-sensitive hypertensive individuals. At this time, it is not known which pathways may be involved. Furthermore, nothing is known about these proposed pathways in children or about possible developmental expression of such mechanisms.

Electrolytes and fluid balance among newborns and infants

A positive sodium balance is necessary at the beginning of life. Although $\sim 30-50 \%$ of the adult body sodium content resides in the skeleton, this proportion is much smaller among infants and small children. Thus, a positive sodium balance is needed during development to build the skeleton and permit growth. Since infancy constitutes the most important and rapid growth period of life, infants need 95-115 mmol sodium per kilogram of weight gain [6]. While urine production begins at $\sim 9-12$ gestational weeks, nephrogenesis is not complete until 35-36 gestational weeks [16, 17]. Glomerular filtration rate (GFR) doubles during the first 2 weeks of life [17], and several tubular transport mechanisms mature after birth [18].

The concentration ability of term neonates is limited, with a maximal urine osmolality of $\sim 700-800 \mathrm{mOsm} / \mathrm{kg} \mathrm{H}_{2} \mathrm{O}$ [16]. Preterm newborns show lower concentration abilities $(\sim 600$ $700 \mathrm{mOsm} / \mathrm{kg} \mathrm{H}_{2} \mathrm{O}$ ). On the other hand, they also have a lower GFR and therefore a reduced ability to excrete water.

Due to tubular immaturity, sodium is often lost during the first 2-3 weeks of life, thereby leading to a negative sodium balance (i.e., the physiological contraction of extracellular volume after birth and compensation for the transepithelial hypotonic water lost) [17]. Nevertheless, the sodium balance is generally maintained in term newborns because the fractional sodium excretion $\left(\mathrm{FE}_{\mathrm{Na}}\right.$ ) stabilizes at $\sim 1 \%$ (or even lower) near the third day of life. In addition, plasma concentrations of renin, angiotensin, and aldosterone are high in newborns, thereby shifting the sodium balance in a positive direction. Plasma concentrations of these mediators decrease during the first weeks of life, in parallel with the maturation of several tubular transporters [16]. Experimental data have shown that sodium plays a role in stimulating growth. The side effects of sodium deprivation were shown at a cell proliferation level in bones and nerves. Chronic sodium depletion retards growth in both experimental rats and humans [17]; thus, due to the increased losses, preterm infants should be supplemented with sodium. In fact, salt lost is greater among preterm and low-birth-weight (LBW) infants [16, 17], placing these children at risk of developing associated negative salt balances and hyponatremia (Fig. 2).

A seminal study demonstrated that preterm infants supplemented with 4-5 $\mathrm{mmol} / \mathrm{kg}$ per day of sodium during the first 2 weeks of life reached a positive sodium balance more rapidly, lost less weight postnatally, and regained birthweight more quickly compared with a control group of nonsupplemented infants (Fig. 2). Interestingly, the effect of this intervention on infant weight remained significant after supplementation ceased [19]. In contrast, full-term infants fed breast milk receive $\sim 1 \mathrm{mmol} / \mathrm{kg}$ per day of sodium, which is enough for an equilibrated growth [6]. Sodium intake $<1 \mathrm{mmol} / \mathrm{kg}$ per day might lead to hyponatremia and growth retardation and should therefore be avoided.

\section{Salt intake during childhood}

Due to regulation mechanisms, the minimal sodium requirement under constant conditions (i.e., after development) is low: in fact, $\sim 0.1 \mathrm{mmol} \mathrm{Na} / 100 \mathrm{kcal}$ might be enough. At the other extreme, humans can tolerate up to $10 \mathrm{mmol} \mathrm{Na}^{+}$/ $100 \mathrm{kcal}$ without experiencing problems [6]. Upper limits for the recommended daily salt intake are given in Table 1. 
Fig. 1 Excess sodium modulates lymphangiogenesis, and osmotically inactive sodium accumulates in the skin interstitium, binding proteoglycans. Excess sodium recruits macrophages, and subsequently activates within subcutaneous macrophages (cells with blue nucleus) a transcription factor, tonicity-enhanced binding protein, which in turn induces the production of the angiogenic protein vascular endothelial growth factor-C. Vascular endothelial growth factor-C stimulates lymphatic vessel (red) growth and creates a new fluid compartment, which buffers the increased body sodium (yellow) and ameliorates the tendency to excess body fluid linked with excess salt intake. Adapted with permission from [15]
Normal $\mathrm{Na}^{+}$Intake

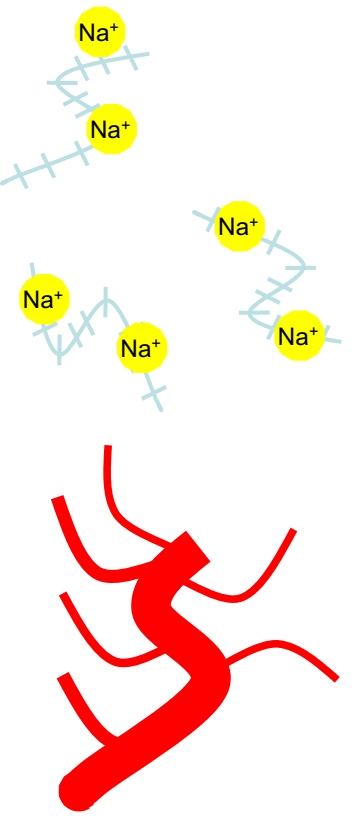

According to data from 1997, 4-year-olds in the UK consumed $4.7 \mathrm{~g} /$ day of salt (i.e., $81.0 \mathrm{mmol} /$ day), whereas 18 year-olds ingested $6.8 \mathrm{~g} /$ day (i.e., $117 \mathrm{mmol} /$ day) [21]. Similar data were recently published regarding the US: 8- to 18-year-

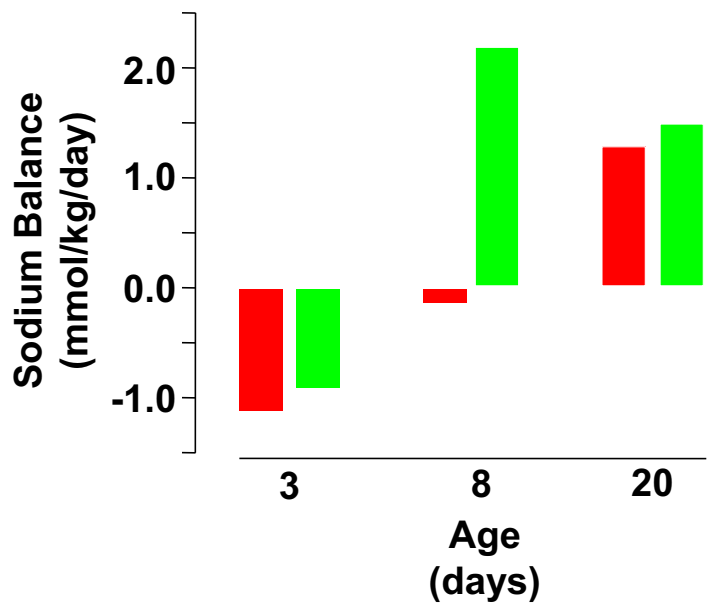

Not-supplemented

\section{Supplemented}

Fig. 2 Sodium balance among preterm infants born at 27-34 gestational weeks. The red histograms show the spontaneous course of sodium balance among normally fed, otherwise healthy, preterm infants. The green histograms depict the course of sodium balance among preterm infants who received a sodium supplementation of $4-5 \mathrm{mmol} / \mathrm{kg} /$ day . Adapted with permission from [19]

\section{High $\mathrm{Na}^{+}$Intake}

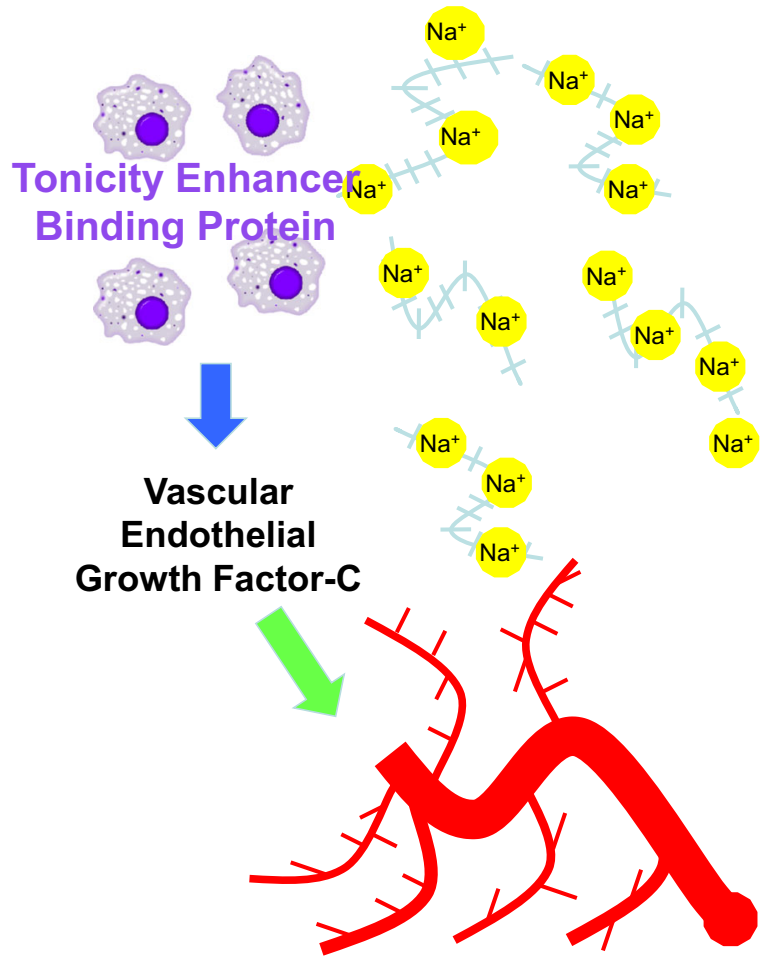

olds had a mean intake of $8.6 \mathrm{~g}$ /day (i.e., $148 \mathrm{mmol} /$ day). In addition, that study noted that salt intake increased with age [22]. Furthermore, salt intake was higher among boys than girls, among normal-weight than overweight participants, and among non-Hispanic white than Hispanic-white and darkskinned participants.

Table 1 summarizes data from several sources regarding actual salt intake among children and compares it with agerecommended salt intakes. The variability among age, sex, and the single studies is considerable. Salt intake increases with age due to differences in total food consumption and food choices [23]. In summary, salt intake is generally $\geq 5.8 \mathrm{~g} /$ day (i.e., $100 \mathrm{mmol} /$ day) starting at $\sim 5$ years of age and increases by $\sim 250 \mathrm{mg} /$ day per year (i.e., $4.3 \mathrm{mmol}$ a day per year) [23]. Very recent data appear to confirm these results [20].

Table 1 Mean and recommended salt intake at different ages

\begin{tabular}{llll}
\hline $\begin{array}{l}\text { Age } \\
\text { (years) }\end{array}$ & $\begin{array}{l}\text { Mean daily salt } \\
\text { intake (g/day) }\end{array}$ & $\begin{array}{l}\text { Range } \\
\text { (g/day) }\end{array}$ & $\begin{array}{l}\text { Recommended daily } \\
\text { salt intake (g/day) }\end{array}$ \\
\hline$<1$ & 0.5 & $0.4-1.3$ & $<1$ \\
$1-5$ & 4 & $3.3-4.9$ & 2 \\
$5-10$ & 6 & $3.7-8.1$ & 4 \\
$10-20$ & 8 & $6.7-11.0$ & 5 \\
\hline
\end{tabular}

To convert a gram of salt to a millimol of sodium, divide by $0.058 \mathrm{~g} /$ mmol. To convert from a gram of salt to a gram of sodium, multiply by $0.397[2,18,20]$ 
Salt intake studies are difficult to conduct. Food diaries, 24-h urinary sodium, overnight urinary sodium, and spot urinary sodium/creatinine ratio, while being adequate assessments of compliance with different salt-intake regimens, are unreliable in accurately assessing absolute dietary salt intakes [24]. In particular, food diaries and urine measurements tend to underestimate salt intake [23]. Available data must therefore be interpreted with caution. Importantly, a tracking phenomenon was identified with respect to salt intake; in other words, a taste habituation is present that generates dietary routines $[25,26]$. Interestingly, boys eat $\sim 20 \mathrm{mmol} /$ day more salt than girls, and dark-skinned children eat $\sim 15 \mathrm{mmol} /$ day more salt than white children [23]. Adults consume $\sim 70-80 \%$ of their salt intake from manufactured foods, snacks, and restaurant and fast-food meals, whereas only $\sim 10 \%$ occurs naturally in foods and another $10 \%$ comes from discretionary use at home (added at the table or during cooking) [23, 27]. Childhood data are limited; however, they seem to globally reflect the adult data [23]. Interestingly, cereals are the largest contributor to dietary salt intake ( $40 \%)$, followed by meat products $(\sim 20 \%)$ and milk products $(\sim 10 \%)[20,23]$.

Effects of salt on blood pressure among children and adolescents

Among older children, excessive salt intake leads to the same complications that are known among adults: volume expansion and arterial hypertension. Several epidemiological, observational and population studies suggest that salt intake is associated with hypertension in children [24, 28]. As stated above, salt-intake studies are difficult to conduct. Nevertheless it is possible to analyze the relative changes in salt intake among children (using any of the methods listed above) in interventional studies [24].

The pioneering study of a salt intake reduction campaign was performed in Japan in the 1950s [24, 29]. This campaign was able to reduce mean salt intake by $\sim 1.5 \mathrm{~g} /$ day (i.e., $26 \mathrm{mmol} /$ day). The effects of this intake reduction were noted among school children over more than 15 years. Several observational studies have not found a significant association between salt and blood pressure; however, they present various methodological problems [24]. In fact, most high-quality studies have demonstrated a significant association between salt intake and hypertension among children [24]. An interesting study was performed based on the National Diet and Nutrition Survey for Young People program undertaken in 1997 in the UK. This study showed that an increase in salt intake of $1 \mathrm{~g}$ /day (i.e., $17.2 \mathrm{mmol} /$ day) increased systolic blood pressure (SBP) by $0.4 \mathrm{mmHg}$ [21] among 4- to 18year-olds. A meta-analysis by $\mathrm{He}$ and $\mathrm{McGregor}$ reviewed ten controlled studies (nine of which were randomized) among children and adolescents and three controlled studies among infants [24]. It is interesting to note that although many studies have been conducted on this topic, the authors of that study found only 13 controlled trials. Furthermore, in several studies, there were important flaws limiting their credibility. The authors calculated the percentage change in salt intake using the qualitatively best available technique: $24-\mathrm{h}$ urinary sodium, overnight urinary sodium, spot urinary sodium/creatinine ratio, or food diary. These measures were used to index saltintake reduction. The child and adolescent studies included in the meta-analysis comprised a total of 966 participants, with a median age of 13 years (range $8-16$ years) and a median saltintake reduction duration 4 of weeks (range 2 weeks to 3 years). Median salt intake reduction was $42 \%$ (interquartile range (IQR) 7-58 \%); this reduction was accompanied by reductions in systolic blood pressure (SBP $(-1.17 \mathrm{mmHg}$, $95 \%$ confidence interval $(\mathrm{CI})-1.78$ to $-0.56 \mathrm{mmHg}$, $p<0.001)]$ and diastolic blood pressure (DBP) $(-1.29 \mathrm{mmHg}$, $95 \% \mathrm{CI}-1.94$ to $-0.65 \mathrm{mmHg}, p<0.0001$ ). After excluding the only nonrandomized study, results were similar, and significance was maintained: SBP $-0.93 \mathrm{mmHg}(95 \% \mathrm{CI}-1.66$ to $-0.20, p=0.01$ ), DBP $-1.07 \mathrm{mmHg}(95 \% \mathrm{CI}-2.00$ to $-0.14 \mathrm{mmHg}, p=0.02$ ). Diet adherence was low in two studies ( $<5 \%$ difference between two diet groups); thus, the authors performed a subanalysis of the studies with relevant adherence. Results were in the same range, and the significance was similar (SBP $-1.18 \mathrm{mmHg}, 95 \% \mathrm{CI}-1.82$ to $-0.55 \mathrm{mmHg}$, $p=0.0003$; DBP $-1.20 \mathrm{mmHg}, 95 \% \mathrm{CI}-1.86$ to $-0.54 \mathrm{mmHg}, p=0.0003)$. Study heterogeneity was not significant, and no evidence of publication bias was detected [24].

The three infant studies comprised 551 participants. Due to the low reliability of DBP measurements during infancy, the authors only examined SBP. Median duration of reduced salt intake was 20 weeks (range 8 weeks to 6 months), and median salt intake reduction was $54 \%$ (IQR 51-79\%). These results were accompanied by an SBP reduction of $-2.47 \mathrm{mmHg}$ ( $95 \% \mathrm{CI}-4.00$ to $-0.94 \mathrm{mmHg}, p<0.01$ ).

\section{Role of potassium}

The daily sodium intake of hypertensive children should be decreased, and their potassium intake should be adequate [28, 30]. Evidence suggests that this dietary intervention has positive short- and long-term effects on blood pressure. In fact, there is a substantial body of literature discussing various dietary and lifestyle interventions possibly capable of reducing blood pressure independently of salt restriction [10]. In particular, a diet rich in fruits and vegetables, low-fat dairy products, and low saturated and total fat (the so-called Dietary Approaches to Stop Hypertension, DASH, diet) was able to decrease blood pressure by $5.5 / 3.0 \mathrm{mmHg}$ [31]. Interestingly, reduction in salt intake and the DASH diet lowered blood pressure significantly, with greater effects in combination than singly [32]. 
The effect of maintaining sufficient potassium intake is most likely smaller than that of maintaining a lower sodium intake [28]. A high potassium intake and a low $\mathrm{Na}^{+} / \mathrm{K}^{+}$ratio appears to positively affect the physiological rise of blood pressure in childhood, resulting in smaller blood pressure slopes [33]. Finally, a study among normotensive African American adolescents showed that potassium supplementation reversed nondipper patients into physiological dipper behavior [34].

Children at increased risk for salt sensitivity

Salt sensitivity is defined as the significant augmentation of arterial blood pressure following increased salt intake. Overweight children $[9,22,28,35]$, children who were born preterm or small for gestational age (SGA) [36], and African American children [28] are at an increased risk of developing high blood pressure when exposed to high salt intake, because these groups present higher prevalence of salt sensitivity.

Overweight children are the most relevant risk group because they represent an intervention population (e.g., via weight-reduction campaigns). Furthermore, the prevalence of childhood obesity has increased [35, 37]. A recent study performed in the USA evaluated the effect of salt on blood pressure among 8- to 18-year-olds, distinguishing between normal-weight and overweight participants [22]. The prevalence of overweight and obesity $(37.1 \%)$ and the prevalence of prehypertension or hypertension $(14.9 \%)$ were high. The authors of that study calculated that participants' SBP increased by $\sim 1 \mathrm{mmHg}$ for each gram of increased sodium intake per day (i.e., $43.5 \mathrm{mmol} /$ day), and this increase was $\sim 1.3 \mathrm{mmHg}$ greater among overweight and obese participants $(1.5 \mathrm{mmHg})$ compared with normal-weight participants $(\sim 0.2 \mathrm{mmHg})$ [22]. However, DBP was not significantly associated with sodium intake. The authors subdivided participants into salt-intake quartiles, and comparison between the lowest and highest quartiles revealed an adjusted hypertension risk of 1.98 . Results of the subanalysis compared normal-weight and overweight children and were even more interesting: the adjusted risk among normal-weight participants was 1.15 , whereas it was 3.51 among overweight and obese children (Fig. 3). The risk for (pre-)hypertension increased by $35 \%$ for each additional gram of sodium per day among normal-weight participants and by $74 \%$ among overweight and obese children. Finally, a relative excess risk due to interaction (RERI) was identified, which means that these risk factors were synergistic. Specifically, they not only increased the global risk by their respective factors but also led to an even greater risk due to their concomitant presence and interaction. The pathophysiological mechanism that develops salt sensitivity in obese children is likely due (among other possibilities) to insulin resistance and

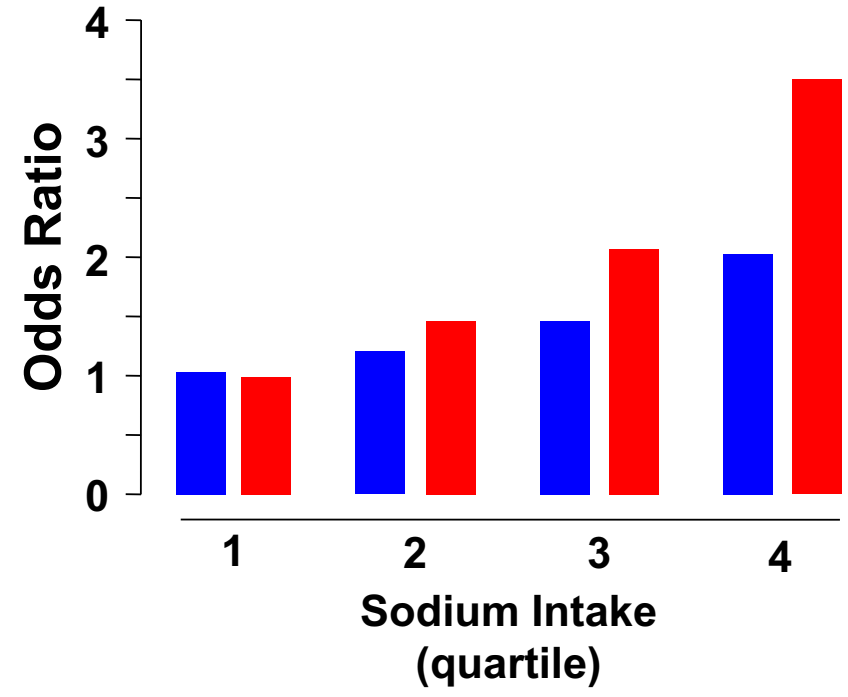

Total

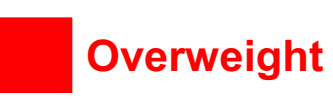

Fig. 3 Odds ratios (ORs) for developing high blood pressure among 6,235 US children 8-18 years old. Children were divided into quartiles based on their sodium intake. The $Y$-axis shows ORs for developing high blood pressure (prehypertension or hypertension). The blue bars depict ORs for all studied participants, and the red bars show the ORs for the subgroup (37.1\%) of overweight and obese children. This graph was developed based on data from Yang et al. [22]

hyperinsulinemia, which activate the renal sympathetic nervous system that causes vasoconstriction and reduces renal blood flow, thereby activating the renin-angiotensin-aldosterone system and inducing salt sensitivity $[9,38,39]$.

The second risk group comprises children born preterm or with low birth weight (LBW). One study found an increased salt-sensitivity risk among children who were of low birth weight (LBW) or small for gestational age (SGA) [36]. The salt-sensitivity prevalence at 7-15 years of age was $37 \%$ among LBW and $47 \%$ among SGA children. These rates were much greater than one might expect in the general adult population. Similar results were found among adults [40].

People at increased cardiovascular risk (e.g., African Americans, patients with hypertension, and people with family history of hypertension) are more likely to have a salt sensitivity than control people [28]. In a well-designed study, sodium retention among African American and white adolescent girls fed low- and high-sodium diets was compared. African American adolescent girls showed a higher retention of sodium compared with Caucasian girls. Thus, a different type of sodium handling might be (partially) responsible for the greater salt-sensitivity prevalence among African Americans [41]. In fact, despite the sodium retention, neither blood pressure nor weight increased, so that the retained sodium had to reside in a nonextracellular compartment [41]. The authors speculated that this compartment is the skeleton [41], but in 
light of the newer findings from Titze and colleagues, it is tempting to assume that this might have been the skin interstitium [14].

\section{Tracking and programming}

The deleterious effect of a high salt intake is not limited to childhood; rather, it has long-lasting effects on blood pressure [26]. High blood pressure in childhood predisposes to hypertension in adulthood and increases the risk of developing cardiovascular disease and premature death [22, 42]. Animal models suggest that salt intake during the first years of life might have a programming effect on blood pressure [24, 43]. In other words, transitory salt exposure during the first years of life might lead to a permanent increase in blood pressure, even when salt intake decreases later in life. In a double-blind randomized trial performed almost 30 years ago among 476 newborn infants divided into low-sodium-diet $(n=231)$ and normal-sodium-diet $(n=245)$ groups, an association was found between salt intake and blood pressure during the first 6 months of life; specifically, a progressive increase in blood pressure was observed among both diet groups across each month of observation [44]. Of the 476 children studied, 167 were recruited for a follow-up assessment 15 years later. SBPs of those fed low-salt diets during their first 6 months of life were significantly lower $(-3.6 \mathrm{mmHg}, 95 \% \mathrm{CI}-6.6$ to $-0.5 \mathrm{mmHg}, p=0.02$ ), although the dietary salt intake did not significantly differ between groups at 15 years of age [45]. This issue, however, is controversial, since the literature offers variable and limited results [46, 47]. In particular, studies denying an association are problematic because they present several flaws limiting their interpretation.

\section{Relevance for public health}

Data regarding salt intake in childhood are relevant, particularly from a public health perspective. First, high blood pressure is an important cause of disease burden measured as Disability Adjusted Life Years (DALY) [48]. Second, a blood-pressure-tracking effect was documented: children with hypertension often mature into adults with hypertension. Third, risk of hypertension appears to be increased with higher sodium intake in childhood. Fourth, taste preferences are imprinted during childhood: children who typically consume a significant amount of salt are likely to prefer salty meals as adults [25]. In fact, salty snacks consumed during childhood might suppress the ability to taste salt, thereby programming salty meal consumption during adulthood [24].

Among Australian children, salt intake led to an increased fluid intake $(r=0.42, p<0.001)$ : each additional gram of salt consumed was associated with an additional 46-g intake of fluids per day. Because two thirds of these children drank sugar-sweetened beverages, their sugar intake increased with their salt intake $(r=0.35, p<0.001)$ : each additional gram of salt was associated with an additional 17-g intake of sugarsweetened beverages per day [49]. In other words, adolescents who consume a significant amount of salt also tend to be overweight. Similar results were found in Great Britain (each additional gram of salt consumed was associated with an additional 27-g intake of sweetened beverages per day) [35]. Based on these data, reducing one's daily salt intake might also contribute to the prevention of obesity and overweight among children $[35,49]$.

\section{Conclusions}

Evidence indicates that reduced salt intake benefits children. Although at the beginning of life a positive sodium balance is required for growth, during the first year of life, a low-salt diet among older children seems to have the same cardiovascularprotective effects known among adults, particularly with respect to blood pressure reduction. Whether salt-intake reduction affects cardiovascular outcomes remains controversial; however, most of the literature currently suggests that a restricted salt intake plays a preventive role [50-53]. A low-salt diet is especially important for overweight children, those born preterm, those born SGA, and those who have hypertension or present nonpreventable cardiovascular risk factors (e.g., family history of hypertension, African American heritage). Salt intake during childhood is relevant for public health: first, elevated blood pressure during childhood predicts elevated blood pressure during adulthood; second, salt intake increases hypertension risk in childhood; third, taste preferences are developed during childhood; fourth, salt intake is often associated with consumption of sugar-sweetened beverages. Further research is needed to identify and evaluate possible preventive interventions on individual and systemic bases during childhood.

Conflict of interest None.

\section{References}

1. Pickering TG (2002) The history and politics of salt. J Clin Hypertens (Greenwich) 4:226-228

2. Kotchen TA, Cowley AW Jr, Frohlich ED (2013) Salt in health and disease-a delicate balance. N Engl J Med 368:1229-1237

3. Ritz E, Mehls O (2009) Salt restriction in kidney disease-a missed therapeutic opportunity? Pediatr Nephrol 24:9-17

4. Hill LL (1990) Body composition, normal electrolyte concentrations, and the maintenance of normal volume, tonicity, and acid-base metabolism. Pediatr Clin N Am 37:241-256

5. Forbes GB, Lewis AM (1956) Total sodium, potassium and chloride in adult man. J Clin Invest 35:596-600 
6. Finberg L, Kravath RE, Hellerstein S (1993) Water and electrolytes in pediatrics - physiology, pathophysiology and treatment, 2nd edn. Saunders, Philadelphia, pp 68-69

7. Holtback U, Aperia AC (2003) Molecular determinants of sodium and water balance during early human development. Semin Neonatol 8:291-299

8. Wadei HM, Textor SC (2012) The role of the kidney in regulating arterial blood pressure. Nat Rev Nephrol 8:602-609

9. Rocchini AP, Key J, Bondie D, Chico R, Moorehead C, Katch V, Martin M (1989) The effect of weight loss on the sensitivity of blood pressure to sodium in obese adolescents. N Engl J Med 321:580-585

10. Frisoli TM, Schmieder RE, Grodzicki T, Messerli FH (2011) Beyond salt: lifestyle modifications and blood pressure. Eur Heart J 32:30813087

11. Khundmiri SJ (2014) Advances in understanding the role of cardioglycosides in renal control of salt homeostasis. J Endocrinol. doi:10.1530/JOE-13-0613

12. Simonetti GD, Mohaupt MG, Bianchetti MG (2012) Monogenic forms of hypertension. Eur J Pediatr 171:1433-1439

13. Meneton P, Jeunemaitre X, de Wardener HE, MacGregor GA (2005) Links between dietary salt intake, renal salt handling, blood pressure, and cardiovascular diseases. Physiol Rev 85:679-715

14. Titze J (2014) Sodium balance is not just a renal affair. Curr Opin Nephrol Hypertens 23:101-105

15. Marvar PJ, Gordon FJ, Harrison DG (2009) Blood pressure control: salt gets under your skin. Nat Med 15:487-488

16. Guignard JP (1982) Renal function in the newborn infant. Pediatr Clin N Am 29:777-790

17. Herin P, Aperia A (1994) Neonatal kidney, fluids, and electrolytes. Curr Opin Pediatr 6:154-157

18. Gattineni J, Baum M (2013) Developmental changes in renal tubular transport-an overview. Pediatr Nephrol. doi:10.1007/s00467-0132666-6

19. Al-Dahhan J, Haycock GB, Nichol B, Chantler C, Stimmler L (1984) Sodium homeostasis in term and preterm neonates. III. Effect of salt supplementation. Arch Dis Child 59:945-950

20. Marrero NM, He FJ, Whincup P, MacGregor GA (2014) Salt intake of children and adolescents in South London: consumption levels and dietary sources. Hypertension 63:1026-1032

21. He FJ, Marrero NM, MacGregor GA (2008) Salt and blood pressure in children and adolescents. J Hum Hypertens 22:4-11

22. Yang Q, Zhang Z, Kuklina EV, Fang J, Ayala C, Hong Y, Loustalot F, Dai S, Gunn JP, Tian N, Cogswell ME, Merritt R (2012) Sodium intake and blood pressure among US children and adolescents. Pediatrics 130:611-619

23. Brown IJ, Tzoulaki I, Candeias V, Elliott P (2009) Salt intakes around the world: implications for public health. Int J Epidemiol 38:791-813

24. He FJ, MacGregor GA (2006) Importance of salt in determining blood pressure in children: meta-analysis of controlled trials. Hypertension 48:861-869

25. Birch LL, Fisher JO (1998) Development of eating behaviors among children and adolescents. Pediatrics 101:539-549

26. Miersch A, Vogel M, Gausche R, Siekmeyer W, Pfaffle R, Dittrich K, Kiess W (2013) Blood pressure tracking in children and adolescents. Pediatr Nephrol 28:2351-2359

27. Mancia G, Fagard R, Narkiewicz K, Redon J, Zanchetti A, Bohm M, Christiaens T, Cifkova R, De Backer G, Dominiczak A, Galderisi M, Grobbee DE, Jaarsma T, Kirchhof P, Kjeldsen SE, Laurent S, Manolis AJ, Nilsson PM, Ruilope LM, Schmieder RE, Sirnes PA, Sleight P, Viigimaa M, Waeber B, Zannad F (2013) 2013 ESH/ESC Guidelines for the management of arterial hypertension: the Task Force for the management of arterial hypertension of the European Society of Hypertension (ESH) and of the European Society of Cardiology (ESC). J Hypertens 31:1281-1357

28. Wilson DKC, Coulon S (2011) Influence of dietary electrolytes on childhood blood pressure. In: Flynn JT, Ingelfinger JR, Portman RJ (eds) Pediatric hypertension, 2nd edn. Springer, New York, pp 259 289

29. Sasaki N (1979) The salt factor in apoplexy and hypertension: epidemiological studies in Japan. In: Yamori Y (ed) Prophylactic approach to hypertensive diseases. Raven, New York, pp 467-474

30. Falkner B, Daniels SR (2004) Summary of the fourth report on the diagnosis, evaluation, and treatment of high blood pressure in children and adolescents. Hypertension 44:387-388

31. Appel LJ, Moore TJ, Obarzanek E, Vollmer WM, Svetkey LP, Sacks FM, Bray GA, Vogt TM, Cutler JA, Windhauser MM, Lin PH, Karanja N (1997) A clinical trial of the effects of dietary patterns on blood pressure. DASH Collaborative Research Group. N Engl J Med 336:1117-1124

32. Sacks FM, Svetkey LP, Vollmer WM, Appel LJ, Bray GA, Harsha D, Obarzanek E, Conlin PR, Miller ER 3rd, Simons-Morton DG, Karanja N, Lin PH; DASH-Sodium Collaborative Research Group (2001) Effects on blood pressure of reduced dietary sodium and the Dietary Approaches to Stop Hypertension (DASH) diet. DASHSodium Collaborative Research Group. N Engl J Med 344:3-10

33. Geleijnse JM, Grobbee DE, Hofman A (1990) Sodium and potassium intake and blood pressure change in childhood. BMJ 300:899-902

34. Wilson DK, Sica DA, Miller SB (1999) Effects of potassium on blood pressure in salt-sensitive and salt-resistant black adolescents. Hypertension 34:181-186

35. He FJ, Marrero NM, MacGregor GA (2008) Salt intake is related to soft drink consumption in children and adolescents: a link to obesity? Hypertension 51:629-634

36. Simonetti GD, Raio L, Surbek D, Nelle M, Frey FJ, Mohaupt MG (2008) Salt sensitivity of children with low birth weight. Hypertension 52:625-630

37. Wang Y, Lobstein T (2006) Worldwide trends in childhood overweight and obesity. Int J Pediatr Obes 1:11-25

38. Bucher BS, Ferrarini A, Weber N, Bullo M, Bianchetti MG, Simonetti GD (2013) Primary hypertension in childhood. Curr Hypertens Rep 15:444-452

39. Flynn J (2013) The changing face of pediatric hypertension in the era of the childhood obesity epidemic. Pediatr Nephrol 28:1059-1066

40. de Boer MP, Ijzerman RG, de Jongh RT, Eringa EC, Stehouwer CD, Smulders YM, Serne EH (2008) Birth weight relates to salt sensitivity of blood pressure in healthy adults. Hypertension 51:928-932

41. Palacios C, Wigertz K, Martin BR, Jackman L, Pratt JH, Peacock M, McCabe G, Weaver CM (2004) Sodium retention in black and white female adolescents in response to salt intake. J Clin Endocrinol Metab 89:1858-1863

42. Franks PW, Hanson RL, Knowler WC, Sievers ML, Bennett PH, Looker HC (2010) Childhood obesity, other cardiovascular risk factors, and premature death. N Engl J Med 362:485-493

43. Dahl LK, Knudsen KD, Heine MA, Leitl GJ (1968) Effects of chronic excess salt ingestion. Modification of experimental hypertension in the rat by variations in the diet. Circ Res 22:11-18

44. Hofman A, Hazebroek A, Valkenburg HA (1983) A randomized trial of sodium intake and blood pressure in newborn infants. JAMA 250: 370-373

45. Geleijnse JM, Hofman A, Witteman JC, Hazebroek AA, Valkenburg HA, Grobbee DE (1997) Long-term effects of neonatal sodium restriction on blood pressure. Hypertension 29:913-917

46. Brion MJ, Ness AR, Davey Smith G, Emmett P, Rogers I, Whincup P, Lawlor DA (2008) Sodium intake in infancy and blood pressure at 7 years: findings from the Avon Longitudinal Study of Parents and Children. Eur J Clin Nutr 62:1162-1169

47. Whitten CF, Stewart RA (1980) The effect of dietary sodium in infancy on blood pressure and related factors. Studies of infants fed salted and unsalted diets for five months at eight months and eight years of age. Acta Paediatr Scand Suppl 279:1-17 
48. Lopez AD, Mathers CD, Ezzati M, Jamison DT, Murray CJ (2006) Global and regional burden of disease and risk factors, 2001: systematic analysis of population health data. Lancet 367:1747-1757

49. Grimes CA, Riddell LJ, Campbell KJ, Nowson CA (2013) Dietary salt intake, sugar-sweetened beverage consumption, and obesity risk. Pediatrics 131:14-21

50. Rebholz CM, He J (2011) Urinary sodium excretion and cardiovascular disease mortality. JAMA 306:1083-1084, author reply 10861087
51. Cook NR (2011) Urinary sodium excretion and cardiovascular disease mortality. JAMA 306:1085, author reply 1086-1087

52. Stolarz-Skrzypek K, Kuznetsova T, Thijs L, Tikhonoff V, Seidlerova J, Richart T, Jin Y, Olszanecka A, Malyutina S, Casiglia E, Filipovsky J, Kawecka-Jaszcz K, Nikitin Y, Staessen JA (2011) Fatal and nonfatal outcomes, incidence of hypertension, and blood pressure changes in relation to urinary sodium excretion. JAMA 305:1777-1785

53. Bochud M, Guessous I, Bovet P (2011) Urinary sodium excretion and cardiovascular disease mortality. JAMA 306:1084, author reply 1086-1087 